\title{
Climate debate must not overheat
}

Charges by parts of the US energy industry that a recent report on global climate change has been 'scientifically cleansed' should not be allowed to undermine efforts to win political support for abatement strategies.

ONE of the most significant implications of the forthcoming presidential and congressional elections in the United States will be their impact on international negotiations about the dangers of man-made global warming. Despite continued dissent from a dwindling band of sceptics, there is growing support within the scientific community for the view, expressed in the latest report from the International Panel on Climate Change (IPCC) (see page 546), that "the balance of evidence suggests a discernible human influence on global climate". The main political task now facing the international community is to turn this conclusion into a plan of action. The extent to which the United States is able to commit itself to this task will be crucial to its success.

There is, therefore, good reason to be concerned about the danger that US politicians may be deflected from this goal by spurious attempts to undermine the validity of the IPCC's conclusions. In the vanguard of such efforts has for several years been the Global Climate Coalition, a group whose description as "an organization of business trade associations and private companies" disguises the extent to which it acts, in particular, as the voice of fossil-fuel producers, primarily in the oil, coal and petroleum industry. Many such bodies are justifiably concerned that attempts to limit the emission of greenhouse gases will impinge on their future activities.

Last week, the GCC published a strongly worded criticism of the IPCC's latest report which, it claimed, had been subject to an institutionalized "scientific cleansing". The pressure group's main target is a chapter in the report of IPCC's Working Group 1 - the panel responsible for assessing the science of climate change - on the detection of such change and the attribution of causes. The GCC's main complaint is that editorial changes were made between the formal approval of this chapter by the full working group at a meeting in Madrid last November and its subsequent appearance in print.

The complaints are not entirely groundless. IPCC officials claim that the sole reason for the revisions was to tidy up the text, and in particular to ensure that it conformed to a 'policymakers' summary' of the full report that was tortuously agreed by government delegates at the Madrid meeting. But there is some evidence that the revision process did result in a subtle shift in the relative weight given to different types of arguments, and that - not surprisingly - this shift tended to favour arguments that aligned with the report's broad conclusions. Conversely, some phrases that might have been (mis)interpreted as undermining these conclusions, particularly if, as IPCC officials feared, they were taken out of context, have disappeared.

The GCC has chosen to express its concern on the question of whether such changes are within the rules of the IPCC. It is certainly an issue that deserves attention. IPCC officials insist that the organization's rules allow changes to be made after draft documents have been accepted in principle by the full working groups. But on a topic where political sensitivities run high, the integrity of the reviewing and approval process is, as in any scientific publishing endeavour, an essential element in assuring the credibility of the resulting conclusions. Public clarification on this point would be useful.

Having said that, however, it is also essential that procedural criticism is not allowed to throw out the baby with the bathwater.
The IPCC's Working Group 1 has taken pains, as its full report indicates, to meet scientific criticisms of its conclusions head on. Inevitably there are those who will continue to dispute the details of its arguments, and others who will be reluctant to sign up to the consensus for reasons of personal caution. Yet the GCC's attack on the IPCC allows direct consideration of the science involved to be overshadowed by semantic arguments that risk losing the wood in the trees. Climate change as a political issue deserves the increasing attention it is likely to obtain as governments in Washington and elsewhere digest the IPCC's conclusions. But it also deserves a more thoughtful and constructive assessment than one that merely seeks to impugn the motives of scientific participants by alleging that they are responding to political pressures.

\section{Replacing Cluster}

European space scientists learnt a hard lesson last week: there is no such thing as a free launch.

TEARS flowed last week along with the burning debris of Cluster's four satellites and Ariane-5's first launcher, which aborted its mission soon after lift-off (see page 541). The first big failure of the European Space Agency (ESA)'s science programme raised an immediate question: should the space agency have risked the price of the whole mission by trusting such a hugely expensive and important project to an untested launcher, just because it was offered a free ride? The answer is yes. ESA officials maintain that the risk of an Ariane-5 launch failure was no greater than that of any other launcher capable of handling the 5-tonne load. They would make the same decision again, they say. And on top of this, the hundreds of millions of ECUs in savings, at a time of general economic strain, cannot be sneezed at.

The real question now is how the scientific community should be compensated for the loss. It is out of the question that the ECU500-million mission should simply be repeated, even though a second attempt would be much cheaper. But it is equally out of the question that Cluster should be written off entirely. The ESA science programme is designed to cover the needs of all space scientists in Europe, and the solar-terrestrial research community cannot be left empty-handed. ESA also has a wider responsibility, as Cluster was a significant element in the coordinated international effort called the Interagency Solar Terrestrial Programme, along with missions from the space agencies of the United States, Japan and Russia.

The question is: what sort of compensatory mission should now be offered, and who should pay for it? Although ESA's space science directorate must be congratulated for tackling this question speedily, money from its own overstretched budget can be given only at some cost to its other planned space science missions. But there is another option. The Cluster/Ariane-5 disaster is a setback for the whole agency, not just its science directorate. The director general of ESA, Jean-Marie Luton, should recognize this, and consider asking the more financially well-endowed launcher directorate to help pay for a new, smaller mission. 